\title{
Infrared thermography as a tool to evaluate body surface temperature and its relationship with feed efficiency in Bos indicus cattle in tropical conditions
}

\author{
Luciane Silva Martello ${ }^{1}$ Saulo da Luz e Silva ${ }^{2}$. Rodrigo da Costa Gomes ${ }^{3}$. \\ Rosana Ruegger Pereira da Silva Corte ${ }^{2}$ Paulo Roberto Leme ${ }^{1}$
}

Received: 18 September 2014 / Revised: 7 May 2015 / Accepted: 11 May 2015

(C) ISB 2015

\begin{abstract}
The aims of this study were to evaluate the use of infrared thermography (IRT) images as a tool for monitoring body surface temperature and to study its relationship with residual feed intake (RFI) in Nellore cattle. We also evaluated IRT as an indicator of feed efficiency in Bos indicus cattle. In this study, 144 Nellore steers were fed high-concentrate diets for 70 days to evaluate feedlot performance. We examined nine animals classified as high RFI and nine animals classified as low RFI by measuring rectal temperature (RT), respiratory frequency (RF), and IRT in the front, eye, ocular area, cheek, flank, ribs, rump, and front feet. The measurements were taken at 0700,1200 , and 1600 hours. The IRT temperatures measured at the eye, cheek, flank, ribs, rump, and front feet were positively associated with RF and RT. These results indicate that increases in the temperatures are associated with increased RF and RT. There was an effect in the RFI group in the front region where IRT correlates with RT. The front IRT for high-RFI cattle was lower $(P<0.01)$ than that for low-RFI cattle. The higher skin temperature measured by IRT for animals in the RFI group may be related to improved efficiency of thermoregulatory mechanisms because the RT remained
\end{abstract}

Electronic supplementary material The online version of this article (doi:10.1007/s00484-015-1015-9) contains supplementary material, which is available to authorized users.

Luciane Silva Martello

martello@usp.br

1 Department of Biosystems Engineering, University of São Paulo (FZEA/USP), Pirassununga Campus, Pirassununga, SP, Brazil

2 Department of Animal Science, University of São Paulo (FZEA/USP), Pirassununga Campus, Pirassununga, SP, Brazil

3 Embrapa Beef Cattle, Campo Grande, MS, Brazil lower in the low-RFI group. IRT can be used in the head for studies related to RFI in beef cattle.

Keywords Beefcattle $\cdot$ Infrared image $\cdot$ Residual feed intake Thermoregulation

\section{Introduction}

Feeding is one of the most important factors in animal production. The costs of feed account for approximately $70 \%$ of the grass-fed cattle system. In feedlot systems, the feed cost accounts for approximately $90 \%$ of the total cost. Thus, the identification of animals that use feed more efficiently will affect both the costs and sustainability of beef production systems.

There are several methods to measure feed efficiency. However, all of the methods require measuring individual feed intake. The individual measure of feed intake is costly, time consuming, and difficult to implement on a large scale. Furthermore, most feed efficiency traits are related to the mature size of an animal and can increase the maintenance requirements. This increase is undesirable for production systems.

Residual feed intake (RFI) is a concept proposed by Koch et al. (1963) and has been revised by many authors (Archer et al. 1997; Basarab et al. 2003; Gomes et al. 2012). The RFI is a criterion for identifying and selecting efficient animals without negatively affecting animal performance, carcass, and meat quality. The RFI concept consists of the deviation of observed versus predicted feed intake adjusted for weight gain. Animals that show negative values (below average) are classified as lower RFI (higher efficiency) than those with positive values (high RFI=lower efficiency). However, determining RFI requires measuring individual animal feed intake 
and it is difficult to make evaluations in a large number of animals.

New traits and methods to indirectly predict the animal efficiency more easily have been studied. Thermoregulation is a factor related to feed efficiency because it is associated with energetic metabolism and energy expenditure (Herd et al. 2004). Thus, thermoregulation could be explored for this purpose. Infrared thermography (IRT) has been used to measure animal body surface temperature in beef cattle (Schaefer et al. 2005; Kortba et al. 2007). Several studies have suggested that more efficient animals have a lower body surface temperature and also produce less methane than less efficient animals (Castro Bulle et al. 2007; Hegarty et al. 2007; Montanholi et al. 2007). According to these authors, smaller maintenance energy requirements are associated with less heat production in more efficient animals. Additionally, the animals lose less heat from their body surface and have a reduced body surface temperature.

Previous studies using IRT have presented promising results for evaluations of feed efficiency using British, continental, or its cross beef breeds in a controlled environment. However, there are no studies examining IRT and feed efficiency in Bos indicus breeds in tropical conditions. These breeds are important for beef production in South and Central America and Asia. Additionally, it is important to assess surface temperature response in regular production conditions and determine if IRT is a useful tool for identifying these variations.

The data from this study could be of primary use to beef industry sectors interested in fast, consistent, accurate, noninvasive, non-destructive, and low-cost methods for animal evaluation to improve the efficiency of production systems.

Our hypothesis is that the body surface temperature of cattle under feedlot conditions differs between feed efficiency groups (high and low RFI), and this difference could be related to thermoregulatory capacity of animals housed in a confined environment.

The aim of this study was to evaluate the use of IRT images as a tool for monitoring the body surface temperature of beef cattle. We also examined the relationship with residual feed intake and thermoregulatory traits in Nellore cattle in tropical conditions.

\section{Material and methods}

This study was conducted at the facilities of the Faculdade de Zootecnia e Engenharia de Alimentos (FZEA) of Universidade São Paulo (USP) in Pirassununga, SP, Brazil, which is located at $21^{\circ} 57^{\prime} 02^{\prime \prime} \mathrm{S}, 47^{\circ} 27^{\prime} 50^{\prime \prime} \mathrm{W}$. The mean elevation is $630 \mathrm{~m}$ above sea level. The average annual temperature is $22^{\circ} \mathrm{C}$, and the area receives approximately $1360 \mathrm{~mm}$ of precipitation annually. The study was conducted according to the Institutional Animal Care and Use Committee Guidelines of FZEA/USP.

The experiment was conducted over two consecutive years and consisted of two phases. In the first phase, a feeding trial was performed to determine the individual RFI of the animals. In the second phase, the cattle were evaluated for body surface temperature using IRT, rectal temperature, and respiratory frequency. The animals were exposed to the natural environmental conditions detailed below in both phases.

In the first phase, a total of 144 Nellore cattle (36 steers and 36 bulls per year) were confined over 2 years (2010 and 2011). The animals were 16 to 21 months of age and had an initial body weight $(\mathrm{BW})$ of $334 \pm 19 \mathrm{~kg}$. The feeding trial was conducted between June and July. The cattle were housed in individual pens and in drylots equipped with Calan Broadbent feeding gates (American Calan, Inc., Northwood, NH, USA). The individual pens were $5 \times 8 \mathrm{~m}$ and contained 36 animals. The other 36 cattle were allotted (12 animals/pen) to one of the three group pens $(10 \times 23 \mathrm{~m})$ with Calan gates (drylots). Individual and group pens were soil surfaced and contained automatic water fountains and sheltered feed bunks. The individual pens had additional shade for animals $\left(20 \mathrm{~m}^{2} /\right.$ head $)$. The drylots had no additional shade for animals. The number of steers and bulls was equally divided between the two facilities.

The animals were fed daily a diet containing $85 \%$ concentrate and $15 \%$ roughage on an ad libitum basis as described in Table 1.

Following a 21-day adaptation period, the animal BW was determined at $\mathrm{d} 0, \mathrm{~d} 21, \mathrm{~d} 42$, and $\mathrm{d} 70$. The average daily gain (ADG) in weight was calculated by linear regression using the time and individual BW.

The dry matter intake (DMI) was calculated as the difference between the quantity provided daily and orts. The RFI of each animal was calculated according the methodology described by Koch et al. (1963) after 70 days of feeding. This calculation considers the difference in observed DMI (DMIobs) and predicted DMI (DMIpred) based on the rate of weight gain and metabolic live weight. DMIpred values were obtained through regression analysis using DMIobs as the dependent variable and $\mathrm{BW}^{0.75}$ and $\mathrm{ADG}$ as independent variables. Animals with RFI greater than the 0.5 standard deviation were classified as high RFI, and cattle with RFI below -0.5 standard deviation were classified as having low RFI. We then selected nine animals classified as high RFI and nine animals with low RFI to participate in the second phase of the study.

In the second phase, the cattle were allotted in individual pens (as described above) for 10 days of IRT and physiological measures of rectal temperature (RT) and respiratory frequency (RF). The measurements of all animals $(2010, n=18$, and $2011, n=18$ ) were collected every day at 0700,1200 , and 1600 hours. The RF was measured by counting flank movements three times for $15 \mathrm{~s}$, and the average was used to 
Table 1 Percentage composition of the diet used (dry matter basis)

\begin{tabular}{lc}
\hline Ingredients & $\%$ of dry matter \\
\hline Corn grain & 41.2 \\
Soybean meal $49 \%$ & 13.6 \\
Citrus pulp & 28.2 \\
Crude sugarcane bagasse & 15.0 \\
Urea & 0.8 \\
Mineral mix & 1.0 \\
Ammonium sulfate & 0.05 \\
Potassium chloride & 0.2 \\
Rumensin ${ }^{\circledR}$ & 0.03 \\
Nutrients & \\
Crude protein, \% & 14.6 \\
Rumen degradable protein, \% & 9.9 \\
TDN, \% & 74.5 \\
\hline
\end{tabular}

${ }^{\mathrm{a}}$ Total digestible nutrients as estimated by Weiss et al. (1992)

calculate movements per minute. The RF was measured with the animals in their pen before the IRT and RT measures, which were collected with the animals restrained in the squeeze chute. The RT was manually collected with a digital thermometer (VMDT01; Viomed ${ }^{\circledR}$ ) simultaneously with IRT.

Infrared thermography was performed using an infrared camera (TI 20-9 Hz, Fluke; Fluke Corporation, Everett, WA, USA). The emissivity value used was 0.98 , which is the recommendation of the camera manufacturer for biological tissues. The IRT images were taken of the following eight body locations: the front, ocular area, cheek, flank, ribs, rump and front feet (Fig. 1), and eye. The animals were brought individually from their pens and placed in the shade immediately prior to IRT collection. The IRT images were taken approximately $1.0 \mathrm{~m}$ from each of the body locations. The images were interpreted using Fluke InsideIRTM 4.0 (Fluke Corporation, EUA) software. The IRT traits defined in this study were the average temperature of a specific shape of each body location photographed (Fig. 2a, b) to define a sub-area of each image. For the ocular area, the maximum temperature within this region was defined as having IRT traits.

The average skin thickness was measured at the beginning of the second phase using Aloka ultrasound equipment model SSD 500 Micrus (Aloka Co., Ltd.) with a 5-MHz linear transducer. An image of each animal was taken in the loin region between the 12th and 13th ribs. The images were recorded on a personal computer for further analysis using Lince ${ }^{\circledR}$ (FZEA/USP, Pirassununga, SP, Brazil) software to determine the skin depth.

A data logger $\left(\mathrm{HOBO}^{\circledR} \mathrm{U} 12\right)$ was installed at the center of the pens $2 \mathrm{~m}$ above the floor, which is approximately the level of the animal's heads. Dry bulb temperature (DBT; ${ }^{\circ} \mathrm{C}$ ) and black globe temperature (BGT; ${ }^{\circ} \mathrm{C}$ ) and relative humidity

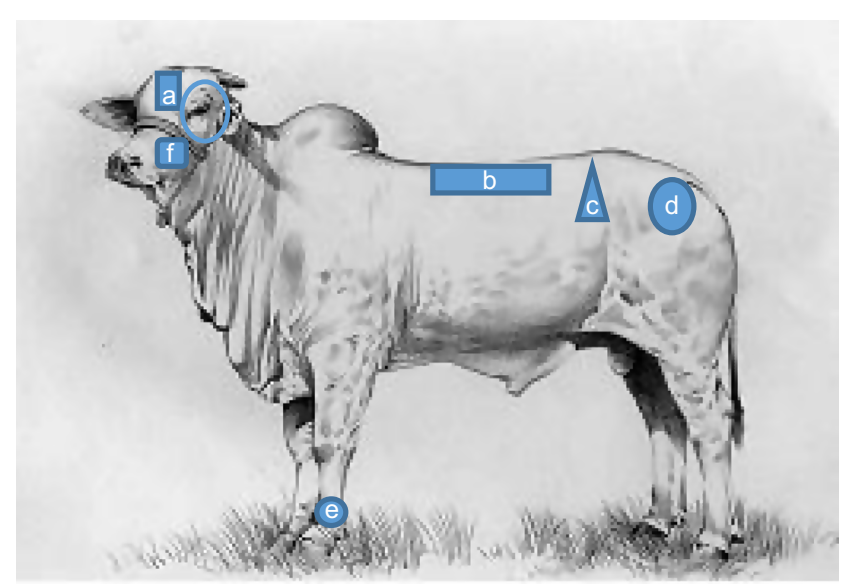

Fig. 1 Illustrative images of the areas of the body where the IRT images were obtained: $a$ front, $b$ ribs, $c$ flank, $d$ rump, $e$ feet, and $f$ cheek

(RH; \%) were automatically recorded $24 \mathrm{~h}$ a day at hourly intervals during the second phase.

The effect of the RFI group and measurement time on IRT traits was analyzed as repeated measurements. The measurement time and RFI group measurement interaction was analyzed as fixed effects. The sex (bulls and steers) and year (2010 and 2011) were analyzed as random effects. The animals were the subject of repeated measurements. The covariance structures were modeled, and the best fit (variance component (VC)) based on the lower value of Akaike information criterion (AIC) was used. The linear regression and correlations were computed to evaluate the association between IRT and physiologic variables. All analyses were conducted using the SAS System software (SAS Institute Inc., Cary, NC, USA).

\section{Results}

There was no interaction between RFI and time of measurements. Thus, the effect for RFI group (low vs. high) on IRT, RT, and FR characteristics can be observed regardless of the time the measurements were taken. Therefore, this study will not focus on how time affects IRT traits.

The average DBT and RH were $26.4 \pm 0.15^{\circ} \mathrm{C}$ (range 18.6 to $29.6^{\circ} \mathrm{C}$ ) and $40 \pm 0.47 \%$, respectively. There is a quadratic association between DBT and hour of the day (Fig. 3). The maximum values of $29.6^{\circ} \mathrm{C}$ occurred at approximately 1400 hours. The temperature remained near the maximum values $\left(29.6{ }^{\circ} \mathrm{C}\right)$ for $4 \mathrm{~h}$ per day from 1200 to 1500 hours.

The mean value of RT was not indicative of animal stress. However, the maximum value of RT observed $\left(39.8^{\circ} \mathrm{C}\right)$ indicated RT values above the normal physiological condition for bovines (Table 2). The maximum value of RF $\left(60 \mathrm{mov} \mathrm{min}^{-1}\right)$ was at the critical limit for bovines (Kolb 1987; Silva 2000).

The average temperatures of IRT were 7 to $2{ }^{\circ} \mathrm{C}$ lower than RT and depended on IRT body area (Table 2). The higher and 
Fig. 2 Illustrative infrared images of the $\mathbf{a}$ front, $\mathbf{b}$ feet, $\mathbf{c}$ ocular area, and $\mathbf{d}$ flank. Observe the specific shape of each body location used
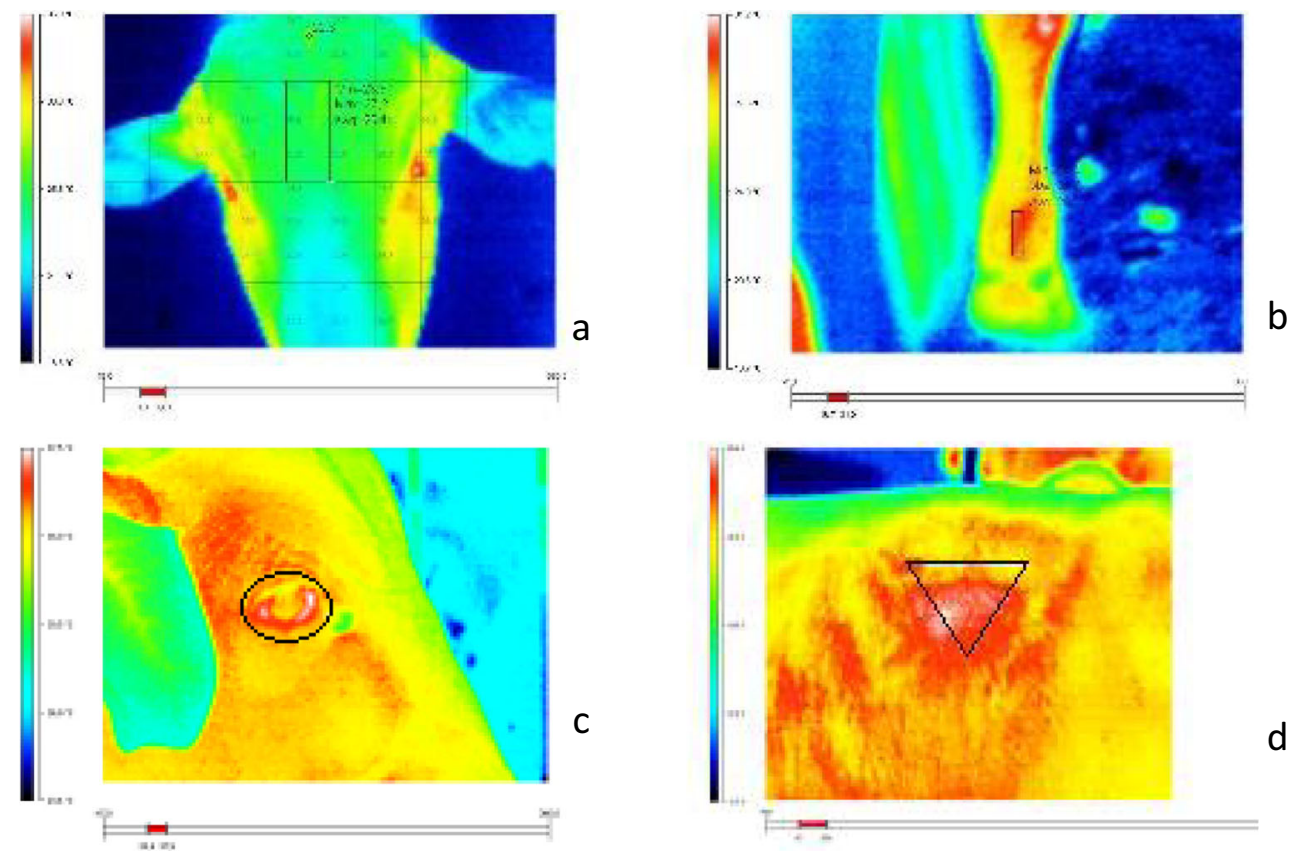

lower differences were for front and ocular area IRT, respectively. Among the regions measured by IRT, temperatures obtained in the ocular area (low eye area) presented higher temperatures and lower variability (standard deviation of 1.05). Portions of the trunk (ribs, flank, and rump) and the cheek presented intermediate temperature values. The animal front and feet presented the lowest temperatures. The front area showed the greatest variability (standard deviation of 3.27). There was no difference between RFI groups for initial and final body weight, average daily gain, and skin thickness (Table 3). The total dry matter intake was smaller, and feed efficiency was greater for the low-RFI group $(P<0.0001)$.

The correlations between IRT and thermoregulatory traits are presented in Table 4. Overall, IRT traits were positively correlated with RT and RF (0.34 to 0.60$)$. The correlations between IRT traits and RT were higher ( 0.43 to 0.60$)$ than among IRT traits and RF (0.35 to 0.49). Considering all IRT traits, eye temperature had the lowest correlation with RT (0.43) and temperature of the ocular area had a low correlation with RF (0.35). The average temperature of the front area had a higher correlation with RT $(0.60)$.

Low-RFI cattle had lower $(P<0.01)$ RT than high-RFI cattle. There were no differences observed for RF. The front IRT was higher $(P<0.01)$ for the low-RFI group than that for the high-RFI group. There were no temperature differences observed for other IRT traits among the RFI groups, and there was no effect on skin thickness in the RFI group (Table 5).

\section{Discussion}

Although the average temperature was not indicative of environmental stress, values above upper critical temperatures for bovines were observed during periods of the day for Nellore
Fig. 3 Estimated and observed values of dry bulb temperature according to the daily hours during the collection period in both years

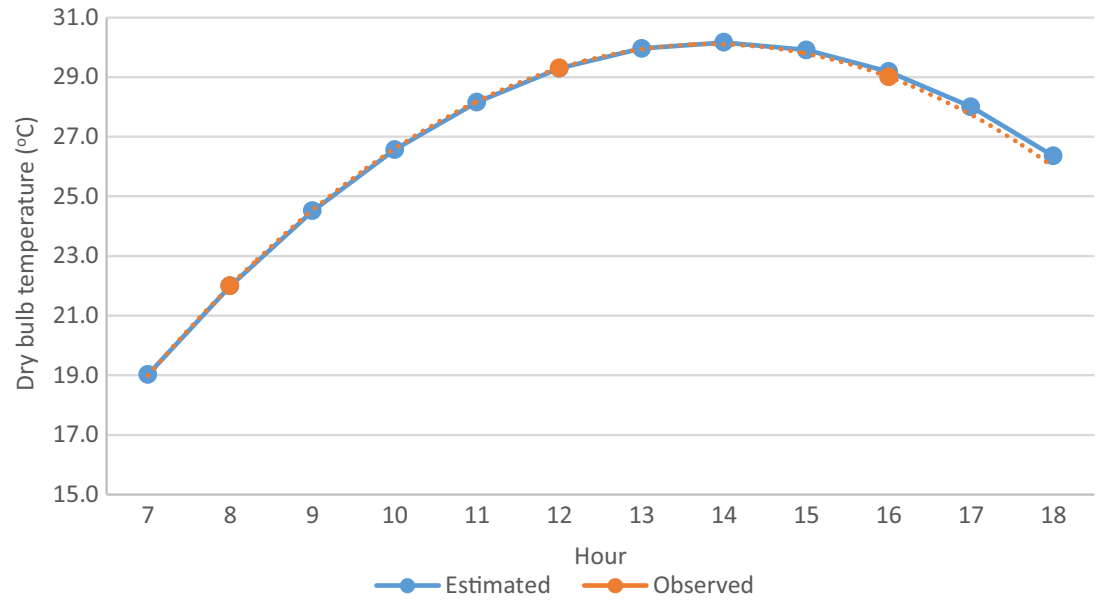


Table 2 Descriptive statistics for efficiency traits and infrared thermography (IRT) traits for both years

\begin{tabular}{lllll}
\hline Traits & Mean & Standard deviation & Minimum & Maximum \\
\hline Initial body weight, $\mathrm{kg}$ & 364 & 25.1 & 320 & 410 \\
Final body weight, $\mathrm{kg}$ & 473 & 33.5 & 404 & 538 \\
Dry matter intake (DMI), kg/day & 10.6 & 1.97 & 7.2 & 14.6 \\
Average daily gain (ADG), kg/day & 1.85 & 0.30 & 1.2 & 2.57 \\
Feed efficiency, g ADG/kg DMI & 180 & 30 & 120 & 290 \\
Residual feed intake, $\mathrm{kg} / \mathrm{day}$ & 0.0 & 1.65 & -2.3 & 2.7 \\
Thickness of skin, $\mathrm{mm}$ & 4.9 & 0.67 & 3.4 & 6.5 \\
Rectal temperature, ${ }^{\circ} \mathrm{C}$ & 38.5 & 0.48 & 35.5 & 39.8 \\
Respiratory frequency, $\mathrm{mov} / \mathrm{min}$ & 27.0 & 8.5 & 16.0 & 60.0 \\
IRT front, ${ }^{\circ} \mathrm{C}$ & 31.4 & 3.24 & 21.3 & 37.6 \\
IRT cheek, ${ }^{\circ} \mathrm{C}$ & 33.6 & 1.97 & 26.4 & 37.7 \\
IRT eye, ${ }^{\circ} \mathrm{C}$ & 33.1 & 1.51 & 28.4 & 37.4 \\
IRT ocular area, ${ }^{\circ} \mathrm{C}$ & 36.5 & 1.05 & 31.7 & 38.9 \\
IRT ribs, ${ }^{\circ} \mathrm{C}$ & 33.2 & 2.39 & 26.5 & 38.5 \\
IRT flank, ${ }^{\circ} \mathrm{C}$ & 33.2 & 2.57 & 24.8 & 38.3 \\
IRT rump, ${ }^{\circ} \mathrm{C}$ & 33.4 & 2.62 & 23.1 & 38.1 \\
IRT feet, ${ }^{\circ} \mathrm{C}$ & 32.5 & 2.47 & 24.5 & 36.6 \\
\hline
\end{tabular}

cattle. According to Baêta and Souza (1997), $27^{\circ} \mathrm{C}$ is the upper critical temperature value for Bos taurus breeds and $29^{\circ} \mathrm{C}$ is the limit for B. indicus (Silanikove 2000). However, the limit could diverge depending on animal adaptation, exposure time to the heat stress, and the level of animal performance (Fuquay 1981; Hahn et al. 1997).

A temperature of approximately $29^{\circ} \mathrm{C}$ for $4 \mathrm{~h}$ was observed in this study. Our data suggest that animals were subjected to mild stress. Additionally, the values of breathing (RF) were close to the limit for cattle. The RT observed (maximum RT) follows the same trend and corroborates the mild stress hypothesis. In environments where air temperature remains above the upper critical limit, the thermoregulatory mechanisms of heat loss are activated to maintain the core body temperature (Fuquay 1981). The heat loss occurs first by conduction, convection, and radiation ways (sensible loss)

Table 3 Least square means, standard error of mean (SEM), and probabilities $(P)$ of performance traits of high- and low-residual feed intake (RFI) groups

\begin{tabular}{llllr}
\hline Traits & High RFI & Low RFI & SEM & $P$ value \\
\hline Initial body weight, $\mathrm{kg}$ & 362 & 365 & 5.2 & 0.6294 \\
Final body weight, kg & 472 & 472 & 6.8 & 0.9630 \\
Dry matter intake, kg/day & 12.2 & 9.0 & 0.25 & $<0.0001$ \\
Average daily gain, kg/day & 1.89 & 1.82 & 0.06 & 0.4346 \\
Feed efficiency, g ADG/kg DMI & 154.8 & 202.2 & 6.7 & $<0.0001$ \\
Residual feed intake, kg/day & 1.6 & -1.6 & 0.15 & $<0.0001$ \\
Thickness of skin, mm & 5.0 & 4.8 & 0.16 & 0.5926 \\
\hline
\end{tabular}

$A D G$ average daily gain, $D M I$ dry matter intake that are dependent on the thermal gradient difference between the environmental temperature and body temperature (Silva 2000). These mechanisms are effective in keeping body heat in equilibrium if the thermal stress is not intense or the thermal stress occurs for a short period as observed in this study. However, in environments where the ambient temperature is above this limit, then evaporation (respiratory and sweating) is used and this mechanism requires greater energy expenditure than other forms of heat loss (Silanikove 2000).

The animal skin temperature could change according to variations in skin blood flow because stress alters the amount of radiated heat that is lost from thermoregulatory sites. The variability of skin temperature follows different patterns depending on the body region. In this study, IRT temperatures were 7 to $2{ }^{\circ} \mathrm{C}$ lower than RT depending on the IRT body area examined. Body temperatures taken closer to external surface are subject to the influence of environmental temperatures and are less stable than deeper body temperatures such as RT (Silva 2000).

Several studies have used IRT to assess skin temperature (Hurnik et al. 1985; Kortba et al. 2007; Montanholi et al. 2008). Berry et al. (2003) observed that udder temperatures were $3-5{ }^{\circ} \mathrm{C}$ cooler than RT. Similar results were reported by Whittow (1962), who verified that the surface rear area was approximately $3{ }^{\circ} \mathrm{C}$ lower than RT. These values are different from the current study, which presented a larger variation between IRT and RT for all body areas except for the ocular area.

In previous studies, Montanholi et al. (2008) and Berry et al. (2003) found IRT temperatures of different body sites varied from $35.38^{\circ} \mathrm{C}$ (rear area) to $30.63{ }^{\circ} \mathrm{C}$ (right front foot), which is similar to the IRT values $\left(36.47\right.$ to $31.4{ }^{\circ} \mathrm{C}$ ) for all 
Table 4 Correlations between infrared thermography traits of different areas (IRT), rectal temperature (RT), and respiratory frequency (RF)

\begin{tabular}{|c|c|c|c|c|c|c|c|c|}
\hline Traits & IRT front & IRT cheek & IRT eye & IRT ocular area & IRT ribs & IRT flank & IRT rump & IRT feet \\
\hline $\mathrm{RT}$ & $0.60 *$ & $0.59 *$ & $0.43 *$ & $0.52 *$ & $0.59 *$ & $0.59 *$ & $0.58 *$ & $0.55^{*}$ \\
\hline $\mathrm{RF}$ & $0.47^{*}$ & $0.43^{*}$ & $0.37 *$ & $0.35^{*}$ & $0.45^{*}$ & $0.45^{*}$ & $0.45^{*}$ & $0.45^{*}$ \\
\hline
\end{tabular}

$* p<0.01$

body sites in the present study. However, the standard deviation (STD) of IRT values in the current study (3.24 to 1.05$)$ is higher than the STD observed in the studies by Montanholi et al. (2008) (0.17 to 0.79) and Berry et al. (2003). The prior studies were conducted in environments with DBT ranging from 11.1 to $27.4{ }^{\circ} \mathrm{C}$ (mean of $18.3^{\circ} \mathrm{C}$ ) (Berry et al. 2003) and from 12.1 to $27.3{ }^{\circ} \mathrm{C}$ (Montanholi et al. 2008). These temperatures can be considered in the thermoneutral zone. Conversely, in the current study, there were fluctuations on IRT temperatures of approximately $16{ }^{\circ} \mathrm{C}$ observed for the same body site (i.e., front). This temperature variation probably occurred because the animals were housed in unsheltered facilities and were subjected to greater variations of environmental conditions, which requires adjustments in the thermoregulatory system. The differences between studies may be explained by the differences in the thermal environmental where cattle were evaluated.

It is known that environmental temperature affects skin surface temperature and influences the thermal exchange between the organism and the environment, especially in mild stress conditions. Pearson's correlations demonstrated that all body temperatures observed were moderately and positively associated with RF and RT. These data indicate that increases in these temperatures are linked to the increase of RF and RT. Similar to our results, Collier et al. (2006) found a positive correlation between RF and body surface temperature ( $r=$ 0.73). In a previous study, Martello et al. (2010) found

Table 5 Mean values and standard errors of mean (SEMs) of infrared thermography traits of different areas (IRT) and thermoregulatory trait measurements by residual feed intake categories

\begin{tabular}{lllll}
\hline Traits & High RFI & Low RFI & SEMs & P value \\
\hline Rectal temperature, ${ }^{\circ} \mathrm{C}$ & 38.6 & 38.5 & 0.01 & 0.0018 \\
Respiratory frequency, mov/min & 27.8 & 28.1 & 0.03 & 0.4051 \\
IRT front & 31.6 & 31.9 & 0.09 & 0.0084 \\
IRT cheek & 33.9 & 33.8 & 0.06 & 0.7911 \\
IRT eye & 33.2 & 33.2 & 0.06 & 0.7566 \\
IRT ocular area & 36.6 & 36.5 & 0.03 & 0.0439 \\
IRT ribs & 33.5 & 33.5 & 0.07 & 0.9407 \\
IRT flank & 33.5 & 33.5 & 0.07 & 0.9708 \\
IRT rump & 33.8 & 33.6 & 0.08 & 0.1137 \\
IRT feet & 32.9 & 32.7 & 0.07 & 0.2106 \\
\hline
\end{tabular}

positive correlations between RF and RT with body surface temperature ( 0.55 and 0.64 , respectively).

The high correlation between IRT front and RT observed in this study could be explained by its proximity to the brain, which houses the central nervous system and is responsible for body temperature regulation (Weschenfelder et al. 2013). Previous studies by Kessel et al. (2010) and McCafferty (2007) considered regions of the head (i.e., brain) as an indicator of core temperature because of its proximity to the brain.

Several studies have evaluated the relationship of ocular area temperature measured with IRT and variations in body core temperature. Tan et al. (2009) reported ocular temperature as an indicator of core temperature $(r>0.80)$ for humans. Additionally, Johnson et al. (2011) found that thermographic eye temperatures are feasible as an index of body temperature for horses in air temperatures of $14.2^{\circ} \mathrm{C}$. These results are different from the data observed in the present study that found a moderate correlation between IRT of the ocular area and RT (0.52) and lower correlation with RF (0.35). The lower correlations obtained in the present study compared to those cited may have two main causes: (1) the data from the studies were obtained from different species (human and equine), and (2) there are differences in the environmental condition during the experimental period of these studies.

Stewart et al. (2008) observed that mild stress responses can be detected as changes in the ocular temperature, as the eye blood flow is tightly related to the sympathetic activity of stress. It is important to highlight that these studies were designed to associate the stress of sympathetic, cognitive, or emotional responses and the present study associated IRT with thermoregulatory traits such as RT and RF. However, these associations could change in different environmental conditions (i.e., chronic thermal stress).

Several studies (Herd et al. 2004; Nkrumah et al. 2007; Basarab et al. 2003) on energy metabolism of beef cattle have demonstrated that more efficient cattle with respect to RFI traits are related with low heat production and lower maintenance requirements. The thermoregulatory activity is responsible for extra energy expenditure and increases spending on maintenance requirements.

One of the first physiologic changes that occurs in bovines in response to heat stress is the temperature change of the body surface. These changes occur due to circulatory adjustments that allow the blood flow to circulate in peripheral vessels of the body and permit heat exchange between the animal and 
the environment (Montanholi et al. 2009). In this situation, changes in temperature of the body surface may occur.

The finding that IRT of different body locations presented different relationships with RFI was expected because different body locations have different relationships with heat dissipation (Blaxter 1962). In previous studies, body extremities were demonstrated to be the main locations regulating heat loss or storage (Klir and Heath 1992; Van den Heuvel et al. 2004). This finding could justify the results of the current study that the effect of efficiency group (RFI) occurred in extreme regions (e.g., head region as IRT front).

In contrast to our findings, Montanholi et al. (2008) evaluated thermography for assessing heat production and found a stronger relationship between heat production and feet temperature $(r=0.88, P<0.001)$. In another study, Montanholi et al. (2009) determined the relationship of IRT, carcass ultrasound, and feed efficiency and the authors found that feet and cheek temperatures were the most promising body locations for indirectly assessing feed efficiency in cattle. However, the frontal region of the head was not evaluated. D'Alterio et al. (2011) found that the daily rhythm foot temperatures were influenced by the variation in the blood flow to the extremities and showed a daily rhythmicity of RT and foot.

The current study was designed to detect variations in surface temperatures of the animals located in their own stalls without any procedure for IRT measures. Therefore, animals were subjected to several factors including dust, moisture, dirt, and mud. These factors may have influenced the accuracy of IRT measures and, especially, of measurement of the feet area. The use of thermography for measuring the temperature of the body surface has the advantage of not being invasive, and it can be used without animal handling. These characteristics allow animals to be examined without interfering in the production system and with minimum stress. Thus, all studied body regions were evaluated without any previous treatment or cleaning. Therefore, in the present study, the feet area was not effective in detecting surface temperature because the constant presence of dirt in this region makes it difficult to measure by IRT.

The temperature of the body locations investigated in this study varied. There were regions with low variation (eye and ocular area) and regions of great variation observed for two points of the head area (IRT point head and IRT of the front). Montanholi et al. (2008) found that body regions with greatest variation were more capable of evaluating feed efficiency in cattle.

All animals require energy for growth of body tissues, and heat will be produced. The heat produced is greatly dissipated through the skin as radiation (Birkett and de Lange 2001; Kleiber 1961). RFI reflects the basal energy requirements, and the caloric input used to supply these requirements results in heat production as an outcome of the metabolic functions (Richardson et al. 2001; Castro Bulle et al. 2007). Thus, the heat dissipated through the skin can be captured by IRT and reflects the energy expenditure of metabolic functions such as thermoregulation. Therefore, the equilibrium of body temperature is directly related with energy expenditure for maintenance requirements.

In a thermoneutral environment, the lower skin temperatures of more efficient steers reflect lower heat production for maintenance requirements and less heat being dissipated by radiation than in less efficient steers (Archer et al. 1999; Montanholi et al. 2008, 2009). Interestingly, in this study, more efficient cattle (lower RFI) presented higher temperatures of the frontal head compared to less efficient cattle (higher RFI). One possible reason for the discrepancy of these results could be related with differences in climatic environment among these studies. In a thermoneutral environment, animals do not activate the thermoregulatory functions and the heat dissipated by radiation reflects the heat expenditure. This heat loss allows us to infer that more efficient animals for RFI have lower skin temperature than less efficient animals (greater RFI).

In conditions of moderate climatic environment with mild stress, as was the situation of this study, it was expected that some animals activate a thermoregulatory mechanism for exchanging sensible and latent heat to achieve body temperature equilibrium. Thus, there is a higher skin temperature measured by IRT for animals of the low-RFI group and this may be related to improved efficiency of thermoregulatory mechanisms. The lower RT values in the low-RFI group supports this hypothesis because the higher skin temperature of this group suggests that the heat dissipated was able to maintain lower body core temperatures than that of the high-RFI group. Therefore, the frontal head is a promising body location for studies related to RFI in beef cattle in tropical conditions.

Other studies using IRT have shown that the temperature of the eye, specifically the temperature of the medial posterior palpebral border of the lower eyelid and the lacrimal caruncle, may be an indicator of stress (Cook et al. 2005; Pavlidis et al. 2002). We found no evidence that ocular area temperatures measured by IRT vary in response to RFI. Many factors are involved with changes of eye temperature because blood flow changes as a result of stress and alters the amount of radiated heat lost from thermoregulatory sites (Hsieh et al. 1990). Additionally, an alerting environmental stimuli or fear response can cause reduction in blood flow and decrease the ear temperatures in rabbits (Blessing 2003) and the tail and paw of rats (Vianna and Carrive 2005). In the present study, although the steers were acclimated with the facilities and human contact for a 70-day period, they may still perceive handling as stressful. The stress could cause temperature changes due to other factors unrelated to efficiency traits or thermoregulation. Montanholi et al. (2008) did not find a considerable association between IRT of the eye and efficiency traits. 
The other four IRT locations such as the cheek, ribs, flank, and rump were not associated with RFI. The ribs and rump areas are influenced by factors such as hair length, which is variable in beef cattle and influences heat dissipation (Arkin et al. 1991). Although these body regions are interesting for thermography measures due to the ease of image acquisition in beef cattle, they are not associated with feed efficiency. Montanholi et al. (2009) did not found important associations between IRT of the rib area and feed efficiency traits.

\section{Conclusions}

The IRT temperatures measured at the eye, cheek, flank, ribs, rump, and front feet were positively associated with RF and $\mathrm{RT}$, which indicates that increases in these temperatures are linked to the increase of RF and RT. Thus, IRT is a promising tool for monitoring body surface temperature.

The IRT of the front of high-RFI cattle was lower than that of low-RFI cattle. The higher skin temperature measured by IRT for animals in the low-RFI group may be related with the improved efficiency of thermoregulatory mechanisms because the RT remained lower in the low-RFI group. The frontal head is a promising body area for studies related to RFI in beef cattle.

Acknowledgments Funding for this study was provided by São Paulo Research Foundation (FAPESP), São Paulo, SP, Brazil.

\section{References}

Archer JA et al (1997) Optimum postweaning test for measurement of growth rate, feed intake, and feed efficiency in British breed cattle. J Anim Sci 75:2024-2032

Archer JA, Richardson EC, Herd RM et al (1999) Potential for selection to improve efficiency of feed use in beef cattle: a review. Aust J Agric Res 50:147-61

Arkin H, Kimmel E, Berman A, Broday D (1991) Heat transfer properties of dry and wet furs of dairy cows. Trans ASAE 34:2550-2558

Baêta FC, Souza CF (1997) Ambiência em edificações rurais - conforto animal. UFV, Viçosa, p 246

Basarab JA et al (2003) Residual feed intake and body composition in young growing cattle. Can J Anim Sci 83:189-204

Berry RJ, Kennedy AD, Scott SL, Kyle BL, Shaefer AL (2003) Daily variation in the udder surface temperature of dairy cows measured by infrared thermography: potential for mastitis detection. Can J Anim Sci 83:687-693

Birkett S, De Lange K (2001) Limitations of conventional models and a conceptual framework for a nutrient flow representation of energy utilization by animals. Br J Nutr 86:647-659

Blaxter KL (1962) The energy metabolism of ruminants. Hutchinson Scientific and Technical, London

Blessing WW (2003) Lower brainstem pathways regulating sympathetically mediated changes in cutaneous blood flow. Cell Mol Biol 23: $527-38$

Castro Bulle FCP, Paulino PV, Sanches AC et al (2007) Growth, carcass quality, and protein and energy metabolism in beef cattle with different growth potentials and residual feed intakes. J Anim Sci 85:928-936

Collier RJ, Dahl GE, Vanbaale MJ (2006) Major advances associated with environmental effects on dairy cattle. J Dairy Sci 89:1244 1253

Cook NJ, Church JS, Schaefer AL, Webster JR, Matthews LR, Suttie JM (2005) Stress and pain assessment of velvet antler removal from Elk (Cervus elaphus canadensis) and Reindeer (Rangifer tarandus). Online J Vet Res 9:13-25

D'Alterio G, Casella S, Gatto M, Gianesella M, Piccione G, Morgante M (2011) Circadian rhythm of foot temperature assessed using infrared thermography in sheep. Czech J Anim Sci 56(7):293-300

Fuquay JW (1981) Heat stress as is affects animal production. J Anim Sci 52:164-174

Gomes RC, Santana MHA, Ferraz JBS, Leme PR, Silva SL (2012) Ingestão de alimentos e eficiência alimentar de bovinos e ovinos de corte. Funpec-Editora, Ribeirão Preto, p 77

Hahn GL, Parkhurrst AM, Gaughan JB (1997) Cattle respiration rate as a function of ambient temperature. Transactions of ASAE. Paper, no. MC 97-121

Hegarty RS et al (2007) Cattle selected for lower residual feed intake have reduced daily methane production. J Anim Sci 85:1479-1486

Herd RM, Oddy VH, Richardson EC (2004) Biological basis for variation on residual feed intake in beef cattle. 1. Review of potential mechanisms. Aust J Exp Agric 44:423-430

Hsieh JC, Chan KH, Lui PW, Lee TY (1990) Clinical application of infrared thermography in diagnosis and therapeutic assessment of vascular ischemic pain. Acta Anaesthesiol Sin 28:493-501

Hurnik JF, Webster AB, DeBoer S (1985) An investigation of skin temperature differentials in relation to estrus in dairy cattle using a thermal infrared scanning technique. J Anim Sci 61(5):1095-1102

Johnson SR, Rao S, Hussey SB, Morley PS, Traub-Dargatz JL (2011) Thermographic eye temperature as an index to body temperature in ponies. J Equine Vet Sci 31:63-66

Kessel L, Johnson L, Arvidsson H, Larsen M (2010) The relationship between body and ambient temperature and corneal temperature. Invest Ophthalmol Vis Sci 51(12):6593-6597

Kleiber M (1961) The fire of life: an introduction to animal energetics. Wiley, New York, p 454

Klir JJ, Heath JE (1992) An infrared thermographic study of surface temperature in relation to external thermal stress in 3 species of foxes - the red fox (Vulpes vulpes), arctic fox (Alopex lagopus), and kit fox (Vulpes macrotis). Physiol Zool 65:1011-1021

Koch RM, Swiger LA, Chambers D et al (1963) Efficiency of feed use in beef cattle. J Anim Sci 22:486-494

Kolb E (1987) Fisiologia veterinária, 4th edn. Guanabara Koogan, Rio de Janeiro, p 612

Kortba R, Knizová I, Kunc P, Bartos L (2007) Comparison between the coat temperature of the eland and dairy cattle by infrared thermography. J Therm Biol 32:355-359

Martello LM, Savastano Junior H, Silva SL, Balieiro JC (2010) Int J Biometeorol. doi:10.1007/s00484-009-0268-6

McCafferty DJ (2007) The value of infrared thermography for research on mammals: previous applications and future directions. Mammal Rev 37:207-223

Montanholi YR, Swanson KC, Miller SP, Palme R, Schenkel FS (2007) Relationships between residual feed intake and infrared thermography and glucocorticoid levels in feedlot steers in three different sire breed. In: Proceedings of the Canadian Nutrition Congress, Winnipeg, M. B, Canada, p. 36

Montanholi YR, Swanson KC, Schenkel FS, McBride BW, Lu D, Miller SP (2008) Assessing feed efficiency in crossbred beef steers through infrared thermography, feeding behavior traits and glucocorticoid levels. Proceedings of X world Conference on Animal Production. Cape Town, p. 62 
Montanholi YR, Swanson KC, Schenkel FS, McBride BW, Caldwell TR, Miller SP (2009) On the determination of residual feed intake and associations of infrared thermography with efficiency and ultrasound traits in beef bulls. Livest Sci 125:22-30

Nkrumah JD et al (2007) Genetic and phenotypic relationships of feeding behavior and temperament with performance, feed efficiency, ultrasound and carcass merit of beef cattle. J Anim Sci 85:2382-2390

Pavlidis I, Eberhardt NL, Levine JA (2002) Human behaviour: seeing through the face of deception. Nature 415:35

Richardson EC, Herd RM, Oddy VH, Thompson JM, Archer JA, Arathur PF (2001) Body composition and implications for heat production of Angus steer progeny of parents selected for and against residual feed intake. Aust J Exp Agric 41:1065-1072

Schaefer AL, Basarab J, Scott S, Colyn J, McCartney D, McKinnon J, Okine E, Tong AKW (2005) The relationship between infrared thermography and residual feed intake in cows. J Anim Sci 83(Supl.1/J):263

Silanikove N (2000) Effects of heat stress on the welfare of extensively managed domestic ruminants. Livest Prod Sci 67:1-18

Silva RG (2000) Introdução à bioclimatologia animal. Nobel, São Paulo, p 286
Stewart M, Stafford KJ, Dowling SK, Schaefer AL, Webster JR (2008) Eye temperature and heart rate variability of calves disbudded with or without local anaesthetic. Physiol Behav 93:789-797

Tan J, Ng EYK, Acharya UR, Chee C (2009) Infrared thermography on ocular surface temperature: a review. Infrared Phys Technol 52:97108

Van den Heuvel CJ, Ferguson SA, Gilbert SS, Dawson D (2004) Thermoregulation in normal sleep and insomnia: the role of peripheral heat loss and new applications for digital thermal infrared imaging (DITI). J Therm Biol 29:457-461

Vianna DML, Carrive P (2005) Changes in cutaneous and body temperature during and after conditioned fear to context in the rat. Eur $\mathrm{J}$ Neurosci 21:2505-12

Weiss WP, Conrad HR, St. Pierre NR (1992) A theoretically-based model for predicting total digestible nutrient values of forages and concentrates. Anim Feed Sci Technol 39:95-110

Weschenfelder AV, Saucie L, Maldague X, Rocha LM, Schaefer AL, Faucitano L (2013) Use of infrared ocular thermography to assess physiological conditions of pigs prior to slaughter and predict pork quality variation. Meat Sci 95:616-620

Whittow GC (1962) The significance of the extremities of the ox (Bos taurus) in thermoregulation. J Agric Sci 58:109-120 